\title{
DOWN SYNDROME AND THE PHONOLOGICAL LOOP: THE EVIDENCE FOR, AND IMPORTANCE OF, A SPECIFIC VERBAL SHORT-TERM MEMORY DEFICIT
}

\author{
Christopher Jarrold, Alan D. Baddeley and Caroline Phillips \\ Centre for the Study of Memory and Learning, \\ Department of Psychology, University of Bristol, UK.
}

\begin{abstract}
Individuals with Down syndrome are thought to perform poorly on tests of verbal short-term memory, such as measures of word span or digit span. This review critically examines the evidence for a specific deficit in verbal shortterm memory in Down syndrome, and outlines a range of possible explanations for such a deficit. The potential implications of a verbal short-term memory impairment for broader aspects of development are outlined, in particular with respect to vocabulary development. Possible intervention strategies, which might improve verbal short-term memory performance in Down syndrome are also considered. However, we argue that further research is needed to fully clarify the nature of a verbal short-term memory deficit in Down syndrome, before the merits of these various intervention approaches can be properly evaluated.
\end{abstract}

Keywords - Down syndrome, verbal short-term memory, phonological loop

\section{Introduction}

Many studies have indicated that individuals with Down syndrome perform poorly on tests of 'verbal short-term memory' - that is, the ability to hold in mind sequences of verbal information such as spoken lists of words or numbers. Typical tests of verbal short-term memory are digit and word span tasks, in which one determines the maximum number of auditorally presented items that an individual can remember and repeat. It is important to note that unusually poor verbal short-term memory is not seen in all individuals with Down syndrome (Vallar \& Papagno, 1993), and is not necessarily specific to Down syndrome, in that it is sometimes seen among individuals with a variety of other learning difficulties (see Hulme \& Mackenzie, 1992; Hulme \& Roodenrys, 1995). However, a verbal short-term memory deficit does appear to be associated with Down syndrome in the sense that groups of individuals with Down syndrome have consistently been shown to be impaired on these tasks, relative to mental age matched controls (e.g., Bower \& Hayes, 1994; Jarrold \& Baddeley, 1997; Jarrold, Baddeley \& Hewes, 1999; Kay-Raining Bird \& Chapman, 1994; MacKay \& McDonald, 1976; Marcell \& Cohen, 1992; Marcell, Harvey \& Cothran, 1988; Marcell, Ridgeway, Sewell \& Whelan, 1995; Marcell \& Weeks, 1988; McDade \& Adler, 1980). 
One theoretical account of short-term memory functioning is Baddeley and Hitch's (1974) 'working memory model'. In this model shortterm storage of information forms part of a broader working memory system in which information is both held and manipulated. The actual storage of verbal information relies on a sub-system of the model termed the phonological loop (see Baddeley, 1986). Consequently digit and word span tasks are seen as measures of phonological loop functioning, and a number of authors have suggested that the relatively poor performance on these tasks shown by individuals with Down syndrome reflects some form of impairment to the phonological loop component of this model (Broadley, MacDonald \& Buckley, 1995; Comblain, 1996; Das \& Mishra 1995; Hulme \& Mackenzie 1992; Jarrold \& Baddeley, 1997; Jarrold et al., 1999; Kay-Raining Bird \& Chapman, 1994; Mackenzie \& Hulme, 1987; Varnhagen, Das \& Varnhagen, 1987; Wang \& Bellugi 1994).

One might argue that proposing a phonological loop deficit in Down syndrome amounts to little more than a redescription of the apparent difficulties in verbal short-term memory. However, this claim does, potentially, advance our understanding of verbal short-term memory difficulties in Down syndrome. This is because the working memory model, and the phonological loop component in particular, are theoretically well-developed and have been heavily researched empirically. In fact there are two important implications of the claim that Down syndrome is associated with a deficit in phonological loop functioning. The first is that our detailed knowledge of intact phonological loop functioning allows us to be more specific about the ways in which performance might break-down in Down syndrome. This in turn will inform the ways in which remediation programmes might be implemented. A second implication is that current evidence suggests that the phonological loop plays an important role in young children's language development. It is thought to be involved in the acquisition of vocabulary in particular, and possibly in reading development as well (see Baddeley, Gathercole \& Papagno, 1998, and below). A phonological loop impairment in Down syndrome would therefore have potential consequences for the development of these abilities.

These two issues, of the form of a verbal shortterm memory deficit in Down syndrome and of its potential consequences, will be addressed later in the paper. However, before these points can be considered one needs to first examine the actual evidence for a verbal short-term memory deficit. Though it is clear that individuals with Down syndrome perform relatively poorly on verbal short-term memory tasks, this does not necessarily imply a specific verbal short-term memory deficit. It may be that individuals perform poorly on all tests of short-term memory, or that performance on tasks such as digit span is constrained by factors other than short-term memory ability. These issues will be examined in the following section of this paper, which reviews the evidence for a specific verbal short-term memory deficit within Down syndrome.

\section{Is there really a specific verbal short-term memory deficit within Down syndrome?}

\section{Is poor performance limited to tests of verbal short-term memory?}

As just discussed, in order to demonstrate that Down syndrome is associated with a memory deficit that is specific to short-term memory for verbal information one needs to show that the deficit does not extend to all tests of short-term memory, such as those tapping memory for visual or spatial information. A number of studies have compared the performance of Down syndrome individuals on tests of verbal and visuo-spatial short-term memory (Bilovsky \& Share, 1965; Bower \& Hayes, 1994; Burr \& Rohr, 1978; KayRaining Bird \& Chapman, 1994; Marcell \& Armstrong, 1982; Rohr \& Burr, 1978). These studies typically show that performance is superior on the visual than on the verbal recall task. Where controls have been employed the Down syndrome participants have been found to be impaired, relative to these controls, on the verbal short-term memory tasks only. However, a 
criticism that might be levelled at these studies (first noted by Marcell \& Armstrong, 1982), is that the tests used to assess verbal and visuospatial short term memory in these cases may not be directly comparable in terms of the method of presentation of the to-be-remembered items, and of the delay interval between presentation and recall. Consequently other authors have compared digit span performance with an analogous visuospatial span task known as Corsi span (Corsi, cited in Milner, 1971). In the Corsi test the participant watches while the experimenter taps on a series of different blocks displayed in front of them, and then has to repeat the series themselves. The sequential presentation of items, coupled by the requirement for immediate serial recall of information makes this task more comparable to digit span, and consequently provides a better test of the specificity of any verbal short-term memory deficit.

At least six studies have compared digit and Corsi performance in Down syndrome, with rather mixed results. Two studies (Haxby, 1989; Vicari, Carlesimo \& Caltagirone, 1995) report broadly equivalent spans on the two tasks, while the remaining four found that Corsi spans were higher than digit spans in their samples (Azari et al., 1994; Jarrold \& Baddeley, 1997; Jarrold, et al., 1999; Wang \& Bellugi, 1994). However, showing an advantage for Corsi spans does not necessarily suggest that verbal short-term memory is impaired in Down syndrome. One cannot assume that performance should be comparable on the two tasks simply because they have the same structure. Instead one needs to show that Corsi spans are unimpaired in Down syndrome, relative to controls, while digit spans are impaired. Of these six studies only Vicari et al. (1995) and Jarrold and Baddeley (1997) employed matched control groups, comparing the performance of individuals with Down syndrome to that shown by typically developing children and individuals with learning disability. While Vicari et al. found that the performance of Down syndrome individuals was comparable to that of controls on both tasks, Jarrold and Baddeley found that their Down syndrome group were impaired only on digit recall. In addition, Jarrold et al. (1999) also compared performance of their Down syndrome group to that shown by other individuals with learning disability. Although this comparison group was not matched for level of ability, differences in verbal and non-verbal ability that existed between the groups were taken into account using statistical techniques which are complementary to a matching approach. Once again performance of the Down syndrome group was found to be relatively impaired for digit span, but not for Corsi span. Therefore, the evidence from our own work strongly supports the view that individuals with Down syndrome show impaired performance on verbal, but not visuospatial short-term memory. However, one would certainly want to see these results replicated by another research group, in a different sample of individuals, before fully accepting this conclusion.

\section{Input and output factors: The potential role of hearing and speech deficits}

Even if one does accept that individuals with Down syndrome perform poorly on digit as opposed to Corsi span tests, this in itself does not prove that they suffer from a specific verbal shortterm memory deficit. This would only follow if poor performance on a digit span task was not caused by any other deficit associated with Down syndrome. In fact there are other factors which could clearly influence performance on verbal short-term memory tests in Down syndrome, even if verbal short-term memory were itself essentially intact. These are potential problems in hearing, and in speech which are commonly associated with Down syndrome.

Verbal short-term memory tests, such as digit span, are typically presented auditorily. Clearly, if an individual has difficulty hearing, identifying, and discriminating stimuli which are being presented to them then their recall is very likely to be poor, regardless of the state of their verbal short-term memory. We know that hearing difficulties are common in Down syndrome (see Davies, 1996), and so could this be the cause of the poor verbal short-term memory performance described above? Two studies have addressed this issue directly. Both Marcell and Cohen (1992) and Jarrold and Baddeley (1997) found measures of 
hearing loss did not correlate with digit span in their samples of children with Down syndrome. However, in the more detailed Marcell and Cohen study, extent of hearing deficits did relate to item identification time. In other words, children with poorer hearing took longer to identify digits, but were no worse at remembering them. This implies that hearing deficits are not a serious input problem in verbal short-term memory. However, it may be that the digits 1 to 9 , which are highly familiar and (with the exception of 5 and 9) relatively easy to discriminate, are less susceptible to the detrimental effects of any hearing loss. Problems of identification would presumably be more marked with less distinct stimuli, such as less familiar non-digit words.

Two other findings bear on the issue of hearing deficits and of their impact on short-term memory in Down syndrome. Marcell et al. (1988) found that span for auditorally presented digits was no better in a group of children with Down syndrome when digits were presented through headphones than when they presented normally. While these authors do not note whether the volume or clarity of presentation was in fact better with headphones, it seems reasonable to assume that their use might have improved performance if hearing is a problem. Another prediction is that if hearing deficits make discrimination of auditorally presented stimuli particularly difficult for individuals with Down syndrome, then these individuals should be especially susceptible to the effects of similarity among stimuli. The strength of 'acoustic similarity effects' among Down syndrome participants will be reviewed in more detail below, but there it will be seen that there is certainly no evidence that these effects are larger than normal in Down syndrome groups. Therefore, though there is every reason to suppose that hearing loss would make verbal short-term memory tasks difficult for people with Down syndrome, there is actually very little empirical evidence to support this view.

Another possible influence on verbal short-term memory performance is the speed with which individuals can produce a verbal response to the task. A test such as digit span, for example, requires the participant to respond by saying the whole list of items that was presented initially. Baddeley and Hitch's (1974) model of working memory assumes that the strength of a memory trace decays over time. There is evidence to show that the longer individuals take to output the list of items in response to a verbal short-term memory task, the poorer their recall for those items (Cowan Day, Saults, Keller, Johnson \& Flores, 1992; Dosher \& Ma, 1998). In other words, if the first words in a list take a long time to produce, then there is a greater chance of the final words in the list being forgotten before they can be produced. So, if Down syndrome individuals take an unusually long time to respond in these tasks, because of difficulties in articulation (see Dodd, 1975; Gibson, 1978), then they will show corresponding poorer memory performance. Hulme and Mackenzie (1992) found that a group of Down syndrome individuals had significantly slower speech rates than typically developing mental age matched controls, and showed reliably poorer verbal short-term memory span. Though these authors do not claim that slowed articulation is the source of the difficulty seen among individuals with Down syndrome on these tasks, their data is broadly consistent with this suggestion.

If poor verbal short-term memory is the result of speech difficulties leading to longer response times, then removing the need for a verbal response to verbal short-term memory tasks should greatly improve the performance of individuals with Down syndrome. Marcell and Weeks (1988) examined this possibility by contrasting performance in a traditional digit recall task where the response was given verbally, with that shown when a non-verbal response was required. In one experiment this took the form of asking participants to order numbered cards in the correct recall sequence, while in a second experiment participants simply had to point to the appropriate cards in the correct order. Neither response mode improved the performance of the Down syndrome group, relative to controls. Similar results are reported by Laws, MacDonald and Buckley (1996) who found that a pointing response mode did not improve recall in comparison to a standard, verbal serial response. 
These two studies therefore suggest that the need to make an overt verbal response does not artificially lower performance for Down syndrome individuals. Having said this it remains possible that even with a non-verbal response mode, individuals have to verbally repeat the list of numbers to themselves in order to sequence their non-verbal response correctly (Longoni, Richardson \& Aeillo, 1993; Russell, Jarrold \& Henry, 1996). Even if this verbal repetition takes place subvocally the evidence suggests that it would still be constrained by individuals' speech rate (Baddeley \& Wilson, 1985; Bishop \& Robson, 1989), and consequently may well be delayed in Down syndrome. These studies therefore provide no positive evidence that speech production problems impair verbal short-term performance in Down syndrome. At the same time, however, this possibility is not ruled out by this evidence.

\section{What is the nature of a verbal short-term memory deficit?}

If poor performance on digit and word span tasks is not caused by hearing or articulation difficulties affecting the input to, or output from, the phonological loop, then one is left to conclude that the locus of a deficit must lie within the phonological loop itself. As discussed initially, one potential advantage of re-casting the observed verbal short-term memory deficit in Down syndrome in terms of a phonological loop deficit is that our relatively sophisticated knowledge of the structure and function of this system allows us to suggest particular ways in which performance might break down in Down syndrome. These different patterns of deficit will have contrasting implications for remediation (see below).

Figure 1 presents a model of the phonological loop, as developed by Baddeley (1986). An important aspect of this conceptualisation, not present in Baddeley and Hitch's original (1974) model, is that the loop itself consists of two subsystems. These are the phonological store and the process of subvocal rehearsal. Verbal information enters the phonological store, and is held there in a speech-based, phonological code. Evidence for

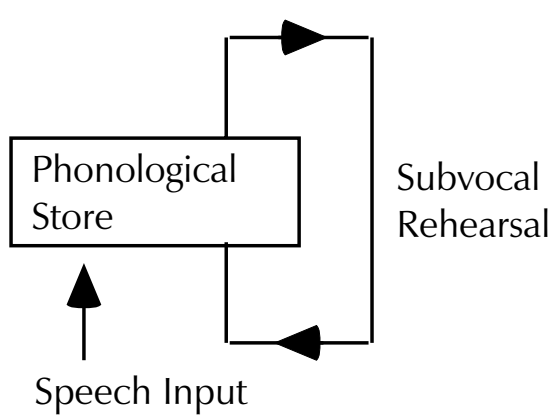

Figure 1. The phonological loop (from Baddeley, 1986)

the fact that information is stored in a phonological code comes from the effect of phonological similarity which is typically seen in verbal short-term memory tasks (Baddeley, 1966; Conrad \& Hull, 1964). Individuals typically show superior short-term memory for dissimilar sounding words than for similar sounding items (e.g., cat, hat, bat, mat). The phonological store is seen as a passive system, and information is lost from the store over time due to the decay of the information held there. However, this decay can be averted by subvocal rehearsal. This is the process of covertly repeating verbal information over and over to oneself. By doing this individuals can prevent the decay of information in the store, by refreshing the traces of items held there. As decay from the store is time based, rehearsal is more efficient the more rapidly one can rehearse items - the faster one rehearses, the larger the number of items that can be refreshed in the store before decay makes them irretrievable. Two related empirical effects provide evidence for this process. Firstly, verbal short-term memory span is directly related to the speed with which typically developing individuals can articulate words (Hitch, Halliday, Dodd \& Littler, 1989; Hulme, Thomson, Muir \& Lawrence, 1984; Nicolson, 1981). Secondly, individuals typically show superior recall for words of a shorter spoken duration than for words of a longer spoken duration (the word length effect; Baddeley, 
Thomson \& Buchanan, 1975). This is because longer words take longer to rehearse, leading to greater decay from the phonological store. ${ }^{1}$

These two aspects of phonological loop functioning, of storage and rehearsal, suggest two ways in which verbal short-term memory might be impaired in Down syndrome. Potential problems in both storage and rehearsal will be discussed here. However virtually all authors who have been specific about the nature of a phonological loop deficit in Down syndrome have suggested that it takes the form of a rehearsal problem (Broadley \& MacDonald, 1993; Comblain, 1996; Hulme \& Mackenzie, 1992). Consequently this possibility will be examined first.

\section{A problem of subvocal rehearsal}

In fact there are two reasons why poor verbal short-term memory might arise as a consequence of problems in rehearsal. On the one hand individuals with Down syndrome might rehearse less efficiently than other individuals. As discussed, the efficiency of rehearsal depends on the rate at which items can be subvocally articulated, thereby preventing decay. If individuals with Down syndrome rehearse more slowly than other individuals then this will lead to reduced verbal short-term memory spans. The other possibility is that individuals with Down syndrome do not tend to engage in rehearsal at all. If this is the case then they will be forced to rely solely on the phonological store, and will suffer from rapid decay of verbal information from short-term memory.

The suggestion of slowed rehearsal is clearly very similar to the notion of delayed output in responding to short-term memory tasks that was discussed above. Both account for verbal shortterm memory problems in terms of an increased impact of time-based decay of information. These accounts differ only in terms of whether they see the main locus of impairment as being within, or

1. In fact some authors would argue that these speech rate effects reflect the impact of speech rate on the time taken to output items from memory, as discussed in the previous section, rather than the time taken to rehearse them (Cowan et al., 1992; Dosher and Ma, 1998). external to, the phonological loop. However, in empirical terms these explanations are very difficult to separate. For example, both are supported by the evidence of slowed speech rates among individuals with Down syndrome (Hulme \& Mackenzie, 1992).

Having said this, Hulme and Mackenzie do not argue for slowed rehearsal in Down syndrome, despite finding slower speech rates in their sample. Instead they suggest that individuals with Down syndrome do not rehearse at all. If this were the case then the actual speech rate of individuals with Down syndrome would be irrelevant, because in the absence of rehearsal there would be no correlation between speech rate and memory span (unless mediated by output delay effects, see above). Indeed Hulme and Mackenzie found that Down syndrome individuals differed from typically developing controls in not showing the same increase in span with increasing speech rate for shorter as opposed to longer words. In other words, Down syndrome individuals failed to show the typically observed word length effect. As this effect is traditionally viewed as a marker of rehearsal, Hulme and Mackenzie saw this as strong evidence for the view that the Down syndrome group were not rehearsing at all.

There are, however, a number of problems with Hulme and Mackenzie's account. Firstly, subsequent studies have found significant effects of word length on short-term recall among individuals with Down syndrome (Broadley, et al., 1995; Comblain, 1996; Laws, 1998; Laws et al., 1996; Laws, MacDonald, Buckley \& Broadley, 1995). This might seem to imply that individuals with Down syndrome are rehearsing in these instances. However, the difficulty in interpreting a significant word length effect is that it may arise as a result of rehearsal, or equally as a consequence of longer words taking longer to output in response to a memory task (Cowan, et al., 1992, as discussed above). Avons, Wright and Pamme (1994) and Henry (1991) have shown that the typical word length effect is substantially reduced if you remove the need for participants to output the whole list of to-be remembered items, and instead simply 'probe' their recall for one single 
item (e.g., asking 'what was the first word?', etc.). This supports the view that the word length effect can arise, at least in part, from output delays. In the light of these results one cannot be certain whether a significant word length effect among individuals with Down syndrome really reflects rehearsal or not. In fact this could only be determined by examining whether a word length effect persisted under probed recall conditions, when output effects are removed. To our knowledge this experiment has yet to be conducted with individuals with Down syndrome. ${ }^{2}$

A second problem for Hulme and Mackenzie's position is that there is evidence that rehearsal does not occur in typically developing children until around the age of seven years (see Gathercole, 1998, for a full review). For example, below the age of seven children do not show a reliable word length effect with probed recall (Henry, 1991). They also show much less reliable relations between speech rate and memory span than are seen among older individuals (Gathercole \& Adams, 1993; Gathercole, Adams \& Hitch, 1994; Henry, 1994). While the groups of individuals with Down syndrome studied in the experiments described above tend to be older than seven, their average mental ages are consistently below the seven year level. As yet we do not know whether chronological age, or equivalent level of mental functioning, determines when individuals with learning disability begin to rehearse. However, it is quite possible that individuals with a mental age of less than seven will not have developed rehearsal strategies. Of course this view is entirely consistent with the suggestion that individuals with Down syndrome

2. Broadley and MacDonald (1993) and Broadley, MacDonald and Buckley (1994) report the use of a probed recall technique in their studies of verbal short-term memory among children with Down's syndrome. However, in both cases single item recall was not probed. Instead the experimenter asked the child to name each item in the list in turn. Similarly, although Laws et al. (1996) employed a non-verbal response mode in their experiment, individuals were required to point to all the items in the list in correct serial order. Clearly neither of these manipulations removes the need to output the whole list, and they may in fact result in longer output times than the standard serial recall procedure. do not rehearse. The importance of this point though is that one might also not expect rehearsal to be occurring among control groups who are also functioning below a seven years equivalent level, or typically developing children who are younger than seven. If both Down syndrome individuals and control groups are unlikely to be rehearsing, then clearly a rehearsal problem cannot explain why individuals with Down syndrome have poorer verbal short-term memory spans than these controls.

\section{A problem of phonological storage}

As an alternative to possible problems in rehearsal, a phonological loop deficit in Down syndrome might take the form of impaired functioning of the phonological store. Unfortunately our understanding of the phonological store is less advanced than is our knowledge of the process of rehearsal, and consequently one can be less specific about the pattern of short-term memory difficulties one would expect to follow from this kind of impairment. Gathercole and Baddeley (1990a), in discussing a study of verbal short-term memory deficits among children with specific language impairment, suggest three ways in which phonological storage might be impaired. They suggest that phonological representations might be noisy or degraded, that the store itself might be of reduced capacity, or that information is lost from the store abnormally rapidly due to unusually fast trace decay.

The first of these three possibilities, of degraded representations, would occur in Down syndrome if hearing difficulties led to degraded information entering the phonological store. The evidence for this has already been discussed above. The other two suggestions have not been directly tested among children with Down syndrome as yet. One might argue that indirect evidence for the capacity of the phonological store comes from studies which have examined the phonological similarity effect among individuals with Down syndrome. As noted above, poorer recall of phonologically similar information is thought to reflect the use of the phonological store, and one might tentatively suggest that the magnitude of this effect might be attenuated if the capacity of the store was 
reduced. This is exactly what was observed by Hulme and Mackenzie (1992) in their studies, where individuals with Down syndrome showed a reliable, but significantly attenuated, phonological similarity effect. Other studies have produced somewhat contrasting results. Broadley et al., (1995) and Comblain (1996) both report significant phonological similarity effects among their samples of individuals with Down syndrome. However, Varnhagen et al., (1987) found that their Down syndrome participants differed from controls in not showing a phonological similarity effect. A potential reason for the absence of an effect in this instance is that Varnhagen et al. asked individuals to remember lists of four items each in their test of the phonological similarity effect. As their participants with Down syndrome only had average digit spans of around two items, lists of four words would have exceeded this group's verbal short-term memory capacity. There is evidence that individuals abandon phonological coding under these conditions (Gathercole \& Baddeley, 1990a; Hall, Wilson, Humphreys, Tinzmann \& Bowyer, 1983; Salamé \& Baddeley, 1986). It therefore appears that individuals with Down syndrome do show significant effects of phonological similarity on verbal short-term memory, but further work is needed to determine whether this effect is smaller in magnitude than that typically observed.

\section{The importance of a verbal short-term memory deficit in Down syndrome, and prospects for intervention}

\section{The importance of a verbal short- term memory deficit}

One of the reasons why there has been considerable research into verbal short-term memory abilities in Down syndrome is because there is evidence that short-term memory plays an important role in the development of aspects of language, and perhaps also of reading ability (see Baddeley et al., 1998). If individuals with Down syndrome really do suffer from a specific verbal short-term memory deficit then this may therefore lead on to problems in these domains. Similarly, if one can improve the short-term memory skills of these individuals via some form of intervention program, then this may also lead on to important benefits in terms of language and reading skills.

The strongest evidence for a role of verbal shortterm memory in determining other aspects of intellectual ability concerns the development of vocabulary. Studies have shown that the ability to pair a novel, unfamiliar word with a known word (the process that is involved in second language learning, e.g., chien-dog) is closely related to verbal short-term memory performance in adults (Baddeley, Papagno \& Vallar, 1988; Papagno, Valentine \& Baddeley, 1991; Papagno \& Vallar, 1992, 1995). More importantly, there is a strong relation between verbal short-term memory ability and native vocabulary level in typically developing children (e.g., Gathercole \& Baddeley, 1989). One possible explanation for this association is that individuals with a higher vocabulary are simply of higher intelligence than their peers, and are likely to perform better on any task simply as a result of this (see Hulme \& Roodenrys, 1995). However, Gathercole, Willis, Emslie and Baddeley (1992) showed that in young children, short-term memory was a direct predictor of subsequent vocabulary development. Similarly, Gathercole and Baddeley (1990b) found that two groups of typically developing children, matched for level of general intelligence but differing in verbal short-term memory ability, learnt new vocabulary items at different rates; with those children with a superior verbal shortterm memory acquiring vocabulary more rapidly.

The clear prediction that follows from these findings, and the evidence of a potential deficit in verbal short-term memory in Down syndrome, is that individuals with Down syndrome should suffer from specific language problems, and in particular, have marked problems in vocabulary acquisition. Bower and Hayes (1994) make this kind of claim explicitly, when they suggest that “... persons with Down syndrome experience specific problems in the area of auditory short-term memory and are therefore among the most language handicapped of the learning disabled 
population." (p.49). In actual fact, though Down syndrome is certainly associated with language delay, the evidence for a particular problem in language acquisition, as opposed to non-verbal development for example, is inconclusive (see Chapman, 1995; Chapman, Schwartz \& KayRaining Bird, 1991). One study has shown that young children with Down syndrome show unimpaired 'fast mapping' - that is, realise that a novel word must relate to a novel object - in vocabulary acquisition (Chapman, Kay-Raining Bird \& Schwartz, 1990). More importantly, other evidence suggests that vocabulary abilities are among the strongest of language skills shown by Down syndrome individuals (see Barrett \& Dinz, 1989; Chapman, 1995). As Laws (1998) notes, this should not be the case if vocabulary development is particularly impaired by a verbal short-term memory problem; although it is possible that other aspects of language acquisition are equally delayed by a verbal short-term memory deficit (see Baddeley et al., 1998). Indeed Laws (1998) found that levels of receptive grammar were more closely related to verbal short-term memory performance in Down syndrome than were vocabulary abilities.

One might also argue that individuals with Down syndrome find some other means of acquiring vocabulary which compensates for their problems in representing novel phonological sounds. In addition to short-term phonological representation, vocabulary acquisition is aided by individuals' long-term knowledge of the lexical and phonological structure of the native language (Baddeley et al., 1998). In Down syndrome the development of long-term knowledge of the language might depend directly on an individual's experience of it, and so might be related closely to chronological age rather than level of intellectual development. If so, this may be an area of relative strength, which consequently may be of greater importance in the acquisition of vocabulary in Down syndrome than would typically be observed. If it is the case that individuals with Down syndrome successfully employ alternative strategies to aid vocabulary acquisition then the practical importance of a verbal short-term memory problem is reduced somewhat.
There is therefore a need for empirical research in this area, to determine which factors constrain vocabulary acquisition in Down syndrome. To our knowledge no study has yet investigated new word learning in Down syndrome in a controlled setting, aside from the fast mapping study noted above which only shows that young children with Down syndrome apply predictable rules to mapping words to objects. This research needs to be carried out, firstly to examine whether children with Down syndrome do have particular difficulties in acquiring new vocabulary, and secondly to determine whether this ability is related to levels of verbal short-term memory. This type of research might also address the question of whether children with Down syndrome compensate for poor verbal short-term memory skills in some way. For example, while one would expect verbal short-term memory to predict vocabulary attainment in typically developing children, one might instead find that chronological age is a better predictor of new word acquisition in Down syndrome.

A possible example of this kind of compensatory adjustment is the evidence that some young children with Down syndrome might be taught to read most effectively with visual rather than phonetic strategies (see Buckley \& Bird, 1993). Individuals can read words either by building the whole word sound from its constituent sounds or phonemes, or by simply learning that a particular visual configuration of letters corresponds to a particular word. While a phonetic approach is ultimately more advantageous, because it allows individuals to read regular words which they have not previously encountered, it appears that some young children with Down syndrome show a surprising facility to associate the visual form of written words with the appropriate verbal response when beginning to read. This may again reflect an adaptive strategy which, in part, reduces the problems in learning to read that might be caused by a verbal short-term memory deficit. Having said this, there is again a lack of experimental evidence on the potential impact of a verbal short-term memory deficit in Down syndrome on the acquisition of reading skills. Though there is in fact evidence to suggest that individual's level of reading ability might itself 
influence verbal short-term memory performance in Down syndrome (Laws, Buckley, Bird, MacDonald \& Broadley, 1995).

\section{Prospects for intervention}

The perhaps unsurprising suggestion that young children with Down syndrome may adapt to overcome problems caused by a verbal short-term memory deficit has clear implications for intervention studies. If, as may be the case for reading, a degree of competence can be achieved by employing an alternative approach to a task, then the most successful intervention might be to accept that problems in verbal short-term memory exist and to concentrate one's efforts in building up strategies for task success in a different domain. The alternative method of intervention is to attempt to improve verbal shortterm memory directly. Clearly these two approaches are diametrically opposed to one another, and consequently deciding between them is not a trivial matter. If it is the case that Down syndrome individuals suffer from a problem in phonological loop functioning, then the nature of that deficit has clear implications for the type of intervention that might best be adopted.

The previous section of this paper outlined how a phonological loop impairment might take one of two possible forms. It may reflect a problem in rehearsal, or a deficit in phonological storage. If the problem is one of rehearsal, whether in terms of inefficient (slow) rehearsal or of an absence of rehearsal altogether, then one should be able to improve verbal short-term memory by training individuals with Down syndrome to rehearse. This intervention strategy is outlined explicitly by Hulme and Mackenzie (1992), though in their work they attempted to train rehearsal among individuals with 'severe learning difficulties', and not individuals with Down syndrome. Instead the most comprehensive studies of the efficacy of rehearsal training have been carried out by researchers at The Sarah Duffen Centre (Broadley \& MacDonald, 1993; Broadley et al., 1994; Laws et al., 1996; Laws, MacDonald, et al., 1995).

In one study Laws, et al., (1996) trained rehearsal among a group of 25 children with Down syndrome, using a cumulative, overt rehearsal strategy. That is, encouraging children to repeat the whole list of items each time a new item is presented to them. The training programme consisted of 18 training sessions, each of 15 minutes duration, spread over a six week period. The average word span of this group increased by approximately 0.4 items in this time. Though this represents a significant improvement, Laws et al. note that it is a small effect. Larger benefits of rehearsal were seen in a separate study carried out by Broadley and MacDonald (1993). These authors used a similar intervention to train rehearsal in a different group of 25 children with Down syndrome. In this case training involved 10 , 10 minute sessions, again spread over a period of six weeks. When tested on a word span task immediately following training, these 25 individuals showed a greater improvement in span scores than a control group of 26 children with Down syndrome who had received no training in this period. The average increase in span for the trained group in this instance was approximately twice that observed by Laws et al. (1996). Two subsequent studies followed-up the group trained by Broadley and MacDonald (1993), at 2, 8 and 36 months after the initial training (Broadley et al., 1994; Laws, MacDonald et al., 1995). These latter assessments showed that the benefits of training were sustained in this group up to 8 months after training. However, this improvement was not maintained after three years.

In addition, Comblain (1994) has also examined the effectiveness of rehearsal training in Down syndrome. She trained cumulative overt rehearsal, first for visually presented items, and then as training progressed for auditorally presented word lists, among a group of 12 individuals with Down syndrome. The intervention programme lasted for eight weeks, and any improvements in verbal short-term memory were examined immediately after training, and then 6 weeks and 6 months later. In line with the results of the Broadley and MacDonald study, Comblain observed a significant benefit of training, which became attenuated over time. Memory span scores for a trained group increased by approximately 1 item initially, but after 6 weeks were only about half an 
item above initial, untrained levels. Nevertheless, this still represented a significant improvement in comparison to an untrained control sample.

These studies show that the performance of individuals with Down syndrome on tests of verbal short-term memory can certainly be improved by rehearsal training. However, the size of this benefit in performance is not always very great, and appears to reduce over time. One other point to note about these studies is that they tend to lack an independent measure of whether rehearsal is being acquired, or is becoming more efficient, as a result of training. This could be done by examining the effect of training on either the magnitude of the word length effect under probed recall conditions, or on the strength of correlations between participant's speech rates and span. These indexes of rehearsal would confirm that the benefits that accrue from training are not simply the result of raised motivational levels or increased familiarity with serial recall tests that might also follow from an intervention.

What is clear is that these relatively short interventions do not equip individuals with a rehearsal strategy that they continue to use long after the training has ended. One potential reason for this failure of long-term maintenance concerns the possibility that individuals with a mental age of less than seven might not be expected to engage in rehearsal anyway (see discussion above). As Comblain (1994) notes, if these individuals are not at a level at which rehearsal would typically be seen, then it may be over-optimistic to expect them to acquire and maintain this skill. In addition, and as discussed above, if this view is correct then a failure to rehearse cannot explain why individuals with Down syndrome have lower memory spans than comparable groups of the same level of development, because none of these groups will be rehearsing. Training rehearsal may well improve the performance of individuals with Down syndrome, but it will not necessarily address the true source of their relative difficulty on these tasks.

The alternative to a relative problem in rehearsal, in terms of phonological loop functioning, is an impairment to the phonological store. Because we lack a very detailed theoretical model of how the store functions, it is much harder to suggest ways in which such a problem could be ameliorated. Indeed, if the store is a passive system which has a reduced capacity or an over-rapid decay rate in Down syndrome, then there may be little if anything that one can do to improve its functioning. In this case intervention may be best aimed at moving away from the need to use verbal short-term memory, to bring in relatively stronger systems. To use an analogy from the work on reading discussed above, one would expect that individuals with Down syndrome might benefit from being asked to remember visual rather than verbal information. Clearly there will always be instances where a visual representation cannot replace a verbal one - for example in the case of a novel item of vocabulary. However, pairing verbal labels with a visual representation of items might provide important additional support for individuals with Down syndrome.

\section{Conclusions}

The data reviewed above support the view that individuals with Down syndrome show particularly poor performance on tests of verbal short-term memory. What is much less clear is whether this deficit really is due to a problem that lies within the phonological loop, and if so, exactly what form that deficit takes. There appear to be at least two reasons why individuals with Down syndrome might show particularly poor performance on these kinds of task that have nothing to do with phonological loop functioning. Both problems of hearing and of articulation would lead to reduced verbal short-term memory spans. If hearing difficulties result in degraded information being stored in verbal short-term memory, then this would also impair individuals' performance in related domains, such as in acquiring new vocabulary. While such a problem clearly has educational implications, it should be lessened considerably by any intervention which directly improves individuals' hearing ability. If the deficit is an output problem, in terms of slow articulation leading to increased delay when individuals respond to a verbal short-term memory task, then the situation is less serious. This kind of deficit would lead to poor verbal short-term memory spans, but it is not clear that 
it would cause any other major difficulties, as verbal short-term memory would be essentially intact in this instance.

If the deficit lies within the phonological loop, then the form of intervention required would appear to depend heavily on the exact nature of any problem. Inefficient or absent rehearsal could be addressed by training rehearsal skills directly. Alternatively, if the problem is one of phonological storage then, given our current knowledge of the phonological store, there might be relatively little that could be done to address this impairment. This is not to say that individuals would not benefit from an intervention program which looked to equip them with alternative strategies to aid memory.

Although one can make suggestions about the type of intervention that would best address each type of difficulty, the problem in this area is that we are still not clear about which problem, or set of problems, individuals with Down syndrome really suffer from. In particular we need to know whether individuals with Down syndrome do take longer to articulate their output from verbal shortterm memory tests than other individuals. We also need to determine whether individuals show a reliable word length effect if tested without the need to output a list of items, as is the case in probed recall. This would indicate whether individuals with Down syndrome do engage in rehearsal, and consequently, whether this is the source of their difficulty in verbal short-term memory tests. Perhaps most crucially, direct and controlled tests of the ability to acquire new vocabulary are needed. Although we have good reason to suspect that a verbal short-term memory deficit in Down syndrome constrains vocabulary acquisition, we have no direct evidence of this. Without this we cannot properly evaluate the broader importance and implications of a verbal short-term memory deficit in Down syndrome.

The aim of this review has been to highlight the potential evidence for a verbal short-term memory deficit in Down syndrome, and to discuss the possible importance of such a deficit. Our hope is that in doing this we have outlined a range of ways in which verbal short-term memory might be sensibly examined and perhaps improved among individuals with Down syndrome. Given the need for further research in order to clarify the exact nature of a verbal short-term memory deficit in Down syndrome, one cannot yet make firm and specific recommendations for intervention. Nevertheless, parents and practitioners should be encouraged to continue to attempt to both improve the short-term memory abilities of children with Down syndrome, and to investigate non-verbal means of structuring and supporting their learning and memory skills.

\section{Acknowledgements}

The authors are supported by a grant from the Medical Research Council to Alan Baddeley and Susan Gathercole. We are grateful to Sue Buckley and Glynis Laws for their helpful comments on a previous draft of this paper.

\section{Correspondence}

\section{Chris Jarrold}

Centre for the Study of Memory and Learning, Department of Psychology, University of Bristol, 8 Woodland Road, Bristol, BS8 1TN, UK.

\section{References}

Avons, S. E., Wright, K. L. \& Pamme, K. (1994). The word-length effect in probed and serial recall. The Quarterly Journal of Experimental Psychology, 47A, 207-231.

Azari, N. P., Horwitz, B., Pettigrew, K. D., Grady, C. L., Haxby, J. V., Giacometti, K. R. \& Schapiro, M. B. (1994). Abnormal pattern of cerebral glucose metabolic rates involving language areas in young adults with Down syndrome. Brain and Language, $46,1-20$.

Baddeley, A. D. (1966). Short-term memory for word sequences as a function of acoustic, semantic and formal similarity. Quarterly Journal of Experimental Psychology, 18, 362-365.

Baddeley, A. D. (1986). Working memory. Oxford: OUP.

Baddeley, A., Gathercole, S. \& Papagno, C. (1998). The phonological loop as a language learning device. Psychological Review, 105, 158-173.

Baddeley, A. D. \& Hitch, G. J. (1974). Working memory. In G. Bower (Ed.), The psychology of learning and motivation (pp. 47-89). New York: Academic Press.

Baddeley, A., Papagno, C. \& Vallar, G. (1988). When long-term learning depends on short-term storage. 
Journal of Memory and Language, 27, 586-596.

Baddeley, A. D., Thomson, N. \& Buchanan, M. (1975). Word length and the structure of short-term memory. Journal of Verbal Learning and Verbal Behavior, 14, 575-589.

Baddeley, A. D. \& Wilson, B. (1985). Phonological coding and short-term memory in patients without speech. Journal of Memory and Language, 24, 490502.

Barrett, M. D. \& Diniz, F. A. (1989). Lexical development in mentally handicapped children. In M. Beveridge, G. Conti-Ramsden \& I. Leudar (Eds.), Language and communication in mentally handicapped people. London: Chapman \& Hall.

Bilovsky, D. \& Share, J. (1965). The ITPA and Down's syndrome: An exploratory study. American Journal of Mental Deficiency, 70, 78-82.

Bishop, D. V. M. \& Robson, J. (1989). Unimpaired short-term memory and rhyme judgement in congenitally speechless individuals: implications for the notion of "articulatory coding". Quarterly Journal of Experimental Psychology, 41A, 123-140.

Bower, A. \& Hayes, A. (1994). Short-term memory deficits and Down's syndrome: A comparative study. Down's Syndrome: Research and Practice, 2, 47-50.

Broadley, I. \& MacDonald, J. (1993). Teaching short term memory skills to children with Down's syndrome. Down's Syndrome: Research and Practice, 1, 56-62.

Broadley, I., MacDonald, J. \& Buckley, S. (1995). Working memory in children with Down's syndrome. Down's Syndrome: Research and Practice, 3, 3-8.

Buckley, S. \& Bird, G. (1993). Teaching children with Down's syndrome to read. Down's Syndrome Research and Practice, 1, 34-39.

Burr, D. B. \& Rohr, A. (1978). Patterns of psycholinguistic development in the severely mentally retarded: a hypothesis. Social Biology, 25, 15-22.

Chapman, R. S. (1995). Language development in children and adolescents with Down syndrome. In P. Fletcher \& B. MacWhinney (Eds.), Handbook of Child Language Oxford: Blackwell.

Chapman, R. S., Kay-Raining Bird, E. \& Schwartz, S. E. (1990). Fast mapping of words in event contexts by children with Down syndrome. Journal of Speech and Hearing Disorders, 55, 761-770.

Chapman, R. S., Schwartz, S. E. \& Kay-Raining Bird, E. (1991). Language skills of children and adolescents with Down syndrome: 1. comprehension. Journal of Speech and Hearing Research, 34, 1106-1120.

Comblain, A. (1994). Working memory in Down's syndrome: Training the rehearsal strategy. Down's Syndrome: Research and Practice, 2, 123-126.

Comblain, A. (1996). Auditivo-vocal short-term memory's functioning in Down's syndrome: Implication for the model of working memory. Approche Neuropsychologique _Des Apprentissages Chez L'Enfant, 8, 137-147.

Conrad, R. \& Hull, A. J. (1964). Information, acoustic confusion, and memory span. British Journal of Psychology, 55, 429-432.

Cowan, N., Day, L., Saults, J. S., Keller, T. A., Johnson, T. \& Flores, L. (1992). The role of verbal output time in the effects of word length on immediate memory. Journal of Memory and Language, 31, 117.

Das, J. P. \& Mishra, R. K. (1995). Assessment of cognitive decline associated with aging: A comparison of individuals with Down syndrome and other etiologies. Research in Developmental Disabilities, 16, 11-25.

Davies, B. (1996). Auditory disorders. In B. Stratford \& P. Gunn (Eds.), New approaches to Down syndrome (pp. 100-121). London: Cassell.

Dodd, B. (1975). Recognition and reproduction of words by Down's syndrome and non-Down's syndrome retarded children. American Journal of Mental Deficiency, 80, 306-311.

Dosher, B. A. \& Ma, J. J. (1998). Output loss or rehearsal loop? Output-time versus pronunciationtime limits in immediate recall for forgettingmatched materials. Journal of Experimental Psychology: Learning, Memory and Cognition, 24, 316-335.

Gathercole, S. E. (1998). The development of memory. Journal of Child Psychology and Psychiatry, 39, 327.

Gathercole, S. E. \& Adams, A. M. (1993). Phonological working memory in very young children. Developmental Psychology, 29, 770-778.

Gathercole, S. E., Adams, A. M. \& Hitch, G. J. (1994). Do young children rehearse? An individual differences analysis. Memory and Cognition, 22, 201-207.

Gathercole, S. E. \& Baddeley, A. D. (1989). Evaluation of the role of phonological STM in the development of vocabulary in children: A longitudinal study. Journal of Memory and Language, 28, 200-215.

Gathercole, S. E. \& Baddeley, A. D. (1990a). Phonological memory deficits in language disordered children: Is there a causal connection. Journal of Memory and Language, 29, 336-360.

Gathercole, S. E. \& Baddeley, A. D. (1990b). The role of phonological memory in vocabulary acquisition: A study of young children learning new words. British Journal of Psychology, 81, 439-454.

Gathercole, S. E., Willis, C. S., Emslie, H. \& Baddeley, A. D. (1992). Phonological memory and vocabulary development during the early school years: A longitudinal study. Developmental Psychology, 5, 887-898. 
Gibson, D. (1978). Down's syndrome: the psychology of mongolism. Cambridge: Cambridge University Press.

Hall, J. W., Wilson, K. P., Humphreys, M. S., Tinzmann, M. B. \& Bowyer, P. M. (1983). Phonemic-similarity effects in good vs. poor readers. Memory and Cognition, 11, 520-527.

Haxby, J. V., Ungerleider, L. G., Horwitz, B., Rapoport, S. I. \& Grady, C. L. (1995). Hemispheric differences in neural systems for face working memory: A PET-rCBF study. Human Brain Mapping, 3, 68-82.

Henry, L. A. (1991). The effects of word length and phonemic similarity in young children's short-term memory. The Quarterly Journal of Experimental Psychology, 43A, 35-52.

Henry, L. A. (1994). The relationship between speech rate and memory span in children. International Journal of Behavioral Development, 17, 37-56.

Hitch, G. J., Halliday, M. S., Dodd, A. \& Littler, J. E. (1989). Development of rehearsal in short-term memory: Differences between pictorial and spoken stimuli. British Journal of Developmental Psychology, 7, 347-363.

Hulme, C. \& Mackenzie, S. (1992). Working memory and severe learning difficulties. Hove: Lawrence Erlbaum Associates.

Hulme, C. \& Roodenrys, S. (1995). Practitioner review: verbal working memory development and its disorders. Journal of Child Psychology and Psychiatry, 36, 373-398.

Hulme, C., Thomson, N., Muir, C. \& Lawrence, A. (1984). Speech rate and the development of shortterm memory span. Journal of Experimental Child Psychology, 38, 241-253.

Jarrold, C. \& Baddeley, A. D. (1997). Short-term memory for verbal and visuo-spatial information in Down's syndrome. Cognitive Neuropsychiatry, 2, 101-122.

Jarrold, C., Baddeley, A. D. \& Hewes, A. K. (1999). Genetically dissociated components of working memory: evidence from Down's and Williams syndrome. Neuropsychologia, 37, 637-651.

Kay-Raining Bird, E. \& Chapman, R. S. (1994). Sequential recall in individuals with Down syndrome. Journal of Speech and Hearing Research, 37, 1369-1380.

Laws, G. (1998). The use of nonword repetition as a test of phonological memory in children with Down syndrome. Journal of Child Psychology and Psychiatry, 39, 1119-1130.

Laws, G., Buckley, S., Bird, G., MacDonald, J. \& Broadley, I. (1995). The influence of reading instruction on language and memory development in children with Down's syndrome. Down's Syndrome: Research and Practice, 3, 59-64.

Laws, G., MacDonald, J. \& Buckley, S. (1996). The effects of a short training in the use of a rehearsal strategy on memory for words and pictures in children with Down syndrome. Down Syndrome: Research and Practice, 4, 70-78.

Laws, G., MacDonald, J., Buckley, S. \& Broadley, I. (1995). Long-term maintenance of memory skills taught to children with Down's syndrome. Down's Syndrome: Research and Practice, 3, 103-109.

Longoni, A. M., Richardson, J. T. E. \& Aiello, A. (1993). Articulatory rehearsal and phonological storage in working memory. Memory and Cognition, 21, 11-22.

MacKay, D. N. \& McDonald, G. (1976). The effects of varying digit message structures on their recall by mongols and non-mongol subnormals. Journal of Mental Deficiency Research, 20, 191-196.

Mackenzie, S. \& Hulme, C. (1987). Memory span development in Down's syndrome, severely subnormal and normal subjects. Cognitive Neuropsychology, 4, 303-319.

Marcell, M. M. \& Armstrong, V. (1982). Auditory and visual sequential memory of Down syndrome and nonretarded children. American Journal of Mental Deficiency, 87, 86-95.

Marcell, M. M. \& Cohen, S. (1992). Hearing abilities of Down syndrome and other mentally handicapped adolescents. Research in Developmental Disabilities, 15, 533-551.

Marcell, M. M., Harvey, C. F. \& Cothran, L. P. (1988). An attempt to improve auditory short-term memory in Down's syndrome individuals through reducing distractors. Research in Developmental Disabilities, 9, 405-417.

Marcell, M. M., Ridgeway, M. M., Sewell, D. H. \& Whelan, M. L. (1995). Sentence imitation by adolescents and young adults with Down's syndrome and other intellectual disabilities. Journal of Intellectual Disability Research, 39, 215-232.

Marcell, M. M. \& Weeks, S. L. (1988). Short-term memory difficulties and Down's syndrome. Journal of Mental Deficiency Research, 32, 153-162.

McDade, H. L. \& Adler, S. (1980). Down syndrome and short-term memory impairment: A storage or retrieval deficit? American Journal of Mental Deficiency, 84, 561-567.

Milner, B. (1971). Interhemispheric differences in the localisation of psychological processes in man. Cortex, 27, 272-277.

Nicolson, R. (1981). The relationship between memory span and processing speed. In M. Friedman, J. P. Das \& N. O'Connor (Eds.), Intelligence and Learning (pp. 179-183). New York: Plenum Press.

Papagno, C. \& Vallar, G. (1992). Phonological shortterm memory and the learning of novel words: The effects of phonological similarity and item length. Quarterly Journal of Experimental Psychology, 44A, 46-67. 
Papagno, C., Valentine, T. \& Baddeley, A. (1991). Phonological short-term memory and foreignlanguage vocabulary learning. Journal of Memory and Language, 30, 331-347.

Papagno, C. \& Vallar, G. (1995). Verbal short-term memory and vocabulary learning in polyglots. Quarterly Journal of Experimental Psychology, 48A, 98-107.

Rohr, A. \& Burr, D. B. (1978). Etiological differences in patterns of psycholinguistic development of children of IQ 30 to 60. American Journal of Mental Deficiency, 82, 549-553.

Russell, J., Jarrold, C. \& Henry, L. (1996). Working memory in children with autism and with moderate learning difficulties. Journal of Child Psychology and Psychiatry, 37, 673-686.

Salamé, P. \& Baddeley, A. (1986). Phonological factors in STM: Similarity and the unattended speech effect. Bulletin of the Psychonomic Society, 24, 263265.

Vallar, G. \& Papagno, C. (1993). Preserved vocabulary acquisition in Down's syndrome: The role of phonological short-term memory. Cortex, 29, 467483.

Varnhagen, C. K., Das, J. P. \& Varnhagen, S. (1987). Auditory and visual memory span: Cognitive processing by TMR individuals with Down syndrome or other etiologies. American Journal of Mental Deficiency, 91, 398-405.

Vicari, S., Carlesimo, A. \& Caltagirone, C. (1995). Short-term memory in persons with intellectual disabilities and Down's syndrome. Journal of Intellectual Disability Research, 39, 532-537.

Wang, P. P. \& Bellugi, U. (1994). Evidence from two genetic syndromes for a dissociation between verbal and visual-spatial short-term memory. Journal of Clinical and Experimental Neuropsychology, 16, 317-322. 